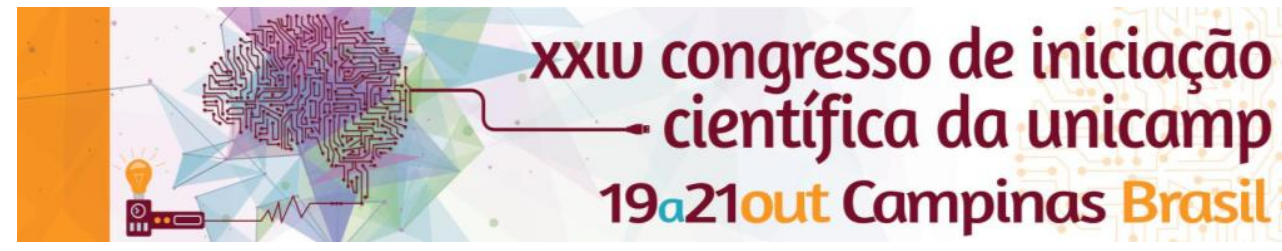

\title{
STATISTICAL ANALYSIS OF HUMAN PROJECTS DEVELOPED IN THE LABORATORY OF STUDIES OF STRESS: STUDY ON INTERNS
}

Pedro H. Fidelis*; Ellen Priscila Nunes de Souza; Aglécio Luiz de Souza; Érica Camargo; Fernando Canova; Filipy

Borghi; Priscila C. Silva; Dora M. Grassi Kassisse

\begin{abstract}
The objective of this study was the standardization of statistical analyses of the projects carried out by the Labeest. Saliva samples were collected along a week of physician residents, interns. Analysis was performed between years of residence and between different days in the same year. Tests of normality followed by parametric and nonparametric analyses where appropriate, the value of $p \leq 5$ was indicative of significance between the data. There were differences between years and days evaluated.
\end{abstract}

Keywords: Interns, Cortisol, Routine.

\section{Introdução}

The correct statistical analysis is very important for the study of biological phenomena. The Laboratory of Stress Study-Labeest receive different proposals for collaborations to evaluate the salivary cortisol with researchers from different areas. In this study we aim, with the support of SAE and fellow of the statistical area, validate and establish a standard analysis of this data. There is also interest in creating a salivary cortisol values database of the population in different age groups, as these data are now nonexistent. For this study in question have been used data from a population of interns. The choice of the population of interns considering criteria stabilized by Souza, $2015^{1}$. Saliva samples were collected in seven consecutive days, as follows: rest, activity, duty and post-duty. In each day collections happened to wake up (6a.m.); before lunch (12p.m.) before dinner (7p.m.) and before bed (11p.m.). The daily production was assessed by calculating the area under the curve (AUC) of each of the days listed. The normality of the data was identified by Kolmogorov-Smirnov, and the statistical differences were evaluated by ANOVA followed by Dunnet, as the results were normal. The significance was set at $p$ $\leq 0.05$. The $p$ value and the number of volunteers are shown in the table. Cortisol was measured by Elisa ${ }^{2,3}$.

\section{Results and Discussion}

The change is evident in the rhythmicity of the volunteers throughout their training, especially in the duty days and post-duty (Figure 1). The weekly routine of this sample showed no significant changes, however this variation becomes significant when compared between years.

Figure 1. Salivary cortisol concentration of interns of the 1st, 2nd and 3rd year in days of rest, activity, duty and post-duty.
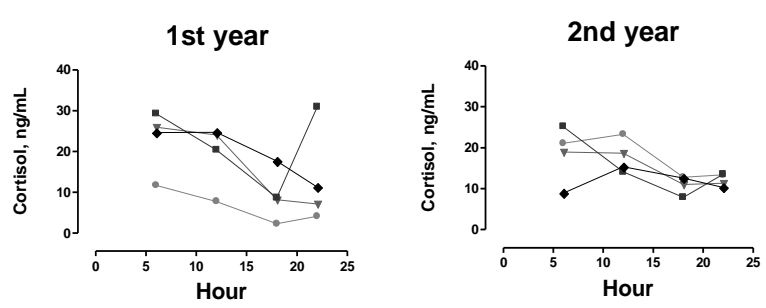

3rd year

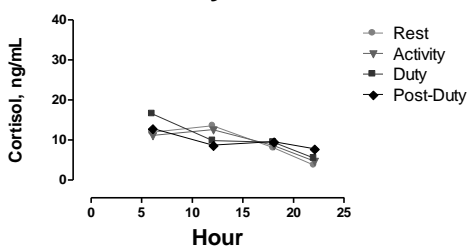

Figure 2. Area under the curve (AUC) of salivary cortisol concentration of interns 1st, 2nd and 3rd year in days of rest, activity, duty and post-duty.

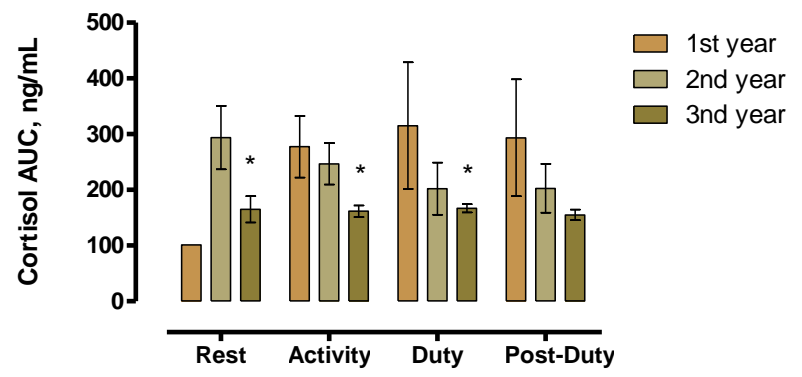

Conclusion

The study identified differences and establish statistical criteria for the study of the data.

\section{Acknowledgment}

Fapesp; Capes, CNPq e SAE

1. Souza, Ellen Priscila Nunes de. Qualidade e Percepção do Ambiente Construído: Influência nas características psicofisiológicas dos usuários. Campinas: Faculdade de Arquitetura e Urbanismo - UNICAMP, 2015. 402p. Tese (Doutorado) - Faculdade de Arquitetura e Urbanismo - UNICAMP, 2015.

2. Batista, J. C., A. L. Souza, H. A. Ferreira, F. Canova, and D. M. GrassiKassisse, 2015, Acute and Chronic Effects of Tantric Yoga Practice on Distress Index: J Altern Complement Med. vol 21, edição 11: 681-685

3. Rocha, M. C. P., M. M. F. Martino, D. Grassi-Kassisse, and A. L. Souza, 2013, Stress among nurses: an examination of salivary cortisol levels on work and day off: Revista Da Escola De Enfermagem Da Usp, v. 47, p. $1187-1194$ 